\title{
Comparação entre Avaliações de Preferência com Itens Tangíveis e com Itens Digitais
}

\author{
Giovana Escobal ${ }^{1}$ \\ Nassim Chamel Elias \\ Celso Goyos \\ Departamento de Psicologia da Universidade Federal de São Carlos, \\ São Carlos, São Paulo, Brasil
}

\begin{abstract}
Resumo
Testes de avaliação de preferência com figuras digitais por computador podem apresentar vantagens em relação aos testes realizados sobre a mesa, como economia de tempo e de esforço e redução de erros manuais. A proposta desse estudo foi examinar o uso de uma avaliação de preferência por computador com 14 crianças com desenvolvimento típico e nove com deficiência intelectual. Dois formatos de avaliação de preferência foram conduzidos para comparar as hierarquias de preferência geradas com figuras digitais e os itens tangíveis correspondentes. Esses formatos incluíam apresentar figuras digitais em um computador e itens tangíveis em uma mesa. Os resultados das avaliações de preferência indicaram que os dois métodos produziram os mesmos itens mais escolhidos para a maioria dos participantes. Muitas variáveis ainda precisam ser examinadas em experimentos futuros. As implicações desses resultados para avaliações de preferência com estímulos digitais são discutidas.
\end{abstract}

Palavras-chave: Avaliação de Preferência, escolha, figuras digitais, itens tangíveis.

\section{Comparison between Preference Assessment with Tangible Items and Digital Items}

\begin{abstract}
Computer-based digital picture preference assessment tests may have boundaries over table-top formats, such as time and effort economy and reduction of manual error. The purpose of this study was to examine the use of a computer-based digital picture preference assessment with 14 children with typical development and nine with intellectual disabilities. Two preference assessment formats were conducted to compare preference hierarchies generated with digital pictures and tangible items. These formats included presenting digital pictures in a computer screen and tangible items on a table. Results of the preference assessments indicated that the two methods yielded same top-ranked items for most participants. Many variables still need to be scrutinized in further experimental studies. The implications of these results for digital stimulus preference assessments are discussed.
\end{abstract}

Keywords: Preference Assessment, choice, digital pictures, tangible items.

Endereço para correspondência: Laboratório de Aprendizagem Humana, Departamento de Psicologia, Universidade Federal de São Carlos, Rod. Washington Luiz, Km 235, São Carlos, SP, Brasil, 13565-905. E-mail: giovanaescobal@hotmail.com,nchamel@terra.com.bre celsogoyos2@gmail.com.

Os autores agradecem o apoio financeiro do Conselho Nacional de Desenvolvimento Científico e Tecnológico (CNPq) e da Fundação de Amparo à Pesquisa do Estado de São Paulo (FAPESP). Agradecimentos especiais a Thomas Sean Higbee, Darlene Crone-Todd e Joseph Pear pela cuidadosa leitura das versões iniciais desse artigo. 


\section{Comparación entre Preferencias con Elementos Concretos y con Elementos Digitales}

\section{Resumen}

Pruebas de evaluación de preferencia con imágenes digitales por ordenador pueden tener ventajas sobre las pruebas realizadas en la mesa, como el ahorro de tiempo y esfuerzo y reducir los errores manuales. El propósito de este estudio fue examinar el uso de una evaluación de preferencia por ordenador con 14 niños con desarrollo típico y nueve con discapacidad intelectual. Dos formatos de evaluación de preferencia fueron realizados para comparar la jerarquía de preferencias generado con fotos digitales y elementos concretos correspondientes. Estos formatos incluyen imágenes digitales de visualización en un ordenador y elementos materiales de una tabla. Los resultados de las evaluaciones de preferencia indicaron que los dos métodos producen los mismos elementos más elegidos para la mayoría de los participantes. Muchas variables aún deben ser examinadas en futuros experimentos. Las implicaciones de estos resultados para las evaluaciones de preferencia con estímulos digitales son discutidas.

Palabras clave: Evaluación de Preferencia, selección, imágenes digitales, elementos concretos.

O reforçamento é um mecanismo central no desenvolvimento de comportamentos operantes (Pace, Ivancic, Edwards, Iwata, \& Page, 1985). Para programar com sucesso uma intervenção baseada nos princípios do reforçamento em pesquisas aplicadas, básicas ou translacionais, é essencial identificar itens de preferência para serem utilizados como possíveis reforçadores com pacientes ou participantes (Piazza, Fisher, Bowman, \& Blakeley-Smith, 1999).

Há um número de avaliações de itens de preferência (AIP) empiricamente demonstrado para determinar hierarquias de preferência, tais como a Avaliação de Preferência com Estímulo Único (Pace et al., 1985), Avaliação de Preferência com Escolha Pareada (Fisher et al., 1992), Avaliação de Preferência com Múltiplos Estímulos (Carr, Nicolson, \& Higbee, 2000; DeLeon \& Iwata, 1996) e Avaliação de Preferência de Operante Livre (Roane, Vollmer, Ringdahl, \& Marcus, 1998).

A Avaliação de Preferência com Escolha Pareada de Fisher et al. (1992) envolve a apresentação de cada estímulo com outro estímulo em uma lista, até que todas as possíveis combinações aos pares sejam apresentadas. As duas maiores vantagens desse método são a possibilidade de (a) produzir uma hierarquia de preferência bem distribuída devido a apresentação aos pares que força o indivíduo a escolher um item, mesmo quando os dois itens podem não ser pre- feridos, e (b) permitir que o indivíduo escolha entre dois ao invés de um conjunto de estímulos a cada oportunidade, considerando que alguns indivíduos não examinam item por item quando muitos estímulos são apresentados simultaneamente (Clausen, 2006; Escobal, Macedo, Duque, Gamba, \& Goyos, 2010).

AIPs tem sido conduzidas com itens tangíveis tais como alimentos, brinquedos e materiais instrucionais (Carr et al., 2000; DeLeon \& Iwata, 1996; Fisher et al., 1992; Pace et al., 1985; Roane et al., 1998) e com formato alternativos de estímulos, tais como figuras impressas e descrições verbais dos estímulos (Conyers et al., 2002; Groskreutz \& Graff, 2009; Hanley, Iwata, \& Lindberg, 1999; Higbee, Carr, \& Harrison, 1999).

Alguns autores tem sugerido que o uso de figuras impressas não geram uma hierarquia de preferência confiável (Hanley et al., 1999; Higbee et al., 1999), principalmente quando a resposta de selecionar uma figura não resulta no acesso ao item correspondente.

Higbee et al. (1999) conduziram um estudo para determinar a possibilidade de usar figuras em avaliações de preferência. Avaliações de preferência com múltiplos estímulos foram conduzidas com dois adultos diagnosticados com deficiência intelectual usando itens tangíveis e cartões com figuras impressas representando os mesmos estímulos. Os resultados indicaram que 
o método com itens tangíveis previu os efeitos reforçadores dos estímulos com maior acurácia que a avaliação com figuras. Há várias possíveis razões pelas quais a avaliação com figuras falhou em determinar reforçadores eficazes acuradamente. Embora os participantes pudessem identificar (tato), oralmente ou através de gestos, os estímulos nos cartões, eles não respondiam (mando) às figuras da mesma maneira que respondiam aos itens tangíveis, talvez pela inexperiência dos participantes em usar figuras para requisitar um item tangível. Outra razão para que os participantes respondessem de forma diferente para os cartões poderia ser a diferença de procedimento entre as duas avaliações. $\mathrm{Na}$ avaliação com itens tangíveis, cada vez que o participante selecionava um item, ele ganhava $20 \mathrm{~s}$ de acesso a esse item. Na avaliação com os cartões, entretanto, a resposta de seleção não resultava no acesso ao item correspondente. Se o acesso ao estímulo for concebido com o reforçador que mantem a resposta de seleção, então, não fornecer acesso ao item seria similar a operação de extinção.

Resultados diferentes foram encontrados por Groskreutz e Graff (2009), que indicaram os mesmos itens mais preferidos para 4 de 5 participantes em três formatos diferentes de avaliação: avaliação tangível com acesso ao item, avaliação com figuras com aceso ao item e avaliação com figuras sem acesso ao item. Entre esses três formatos, a avaliação com figuras sem acesso ao item demorou menos tempo para ser conduzida.

Groskreutz e Graff (2009) pré-testaram habilidades de emparelhamento entre cada figura $\mathrm{e}$ o seu item tangível correspondente, o que pode ser uma habilidade necessária ao substituir itens tangíveis por figuras. Eles também mencionam que avaliações com figuras sem acesso ao item poderiam ser feitas com o auxílio de um computador, que poderia ser mais eficiente em termos de tempo e esforço dos aplicadores, pois o programa é apropriadamente e especificamente desenvolvido para apresentar os estímulos e registrar as respostas de escolha. Então, apresentar figuras digitais através de um programa de computador seria uma extensão do formato de avaliação com figuras impressas apresentados sobre uma mesa.
Esse formato alternativo tem implicações práticas considerando que um banco de dados virtualmente infinito de estímulos (figuras de objetos, alimentos e pessoas, sons de nomes e elogios, e vídeos de atividades, desenhos animados e jogos de computador) está disponível e pode ser acrescido, conforme requisitos de cada nova avaliação. É possível também avaliar itens que não podem ser diretamente apresentados a um indivíduo, como viagens ao shopping ou pegar carona em um carro. Além disso, tentativas em uma avaliação por computador poderiam ser criadas antecipadamente ao momento da avaliação e apresentadas várias vezes, com registro automático dos dados, implicando em economia de tempo e redução de alguns riscos de erros manuais (Escobal, Elias, \& Goyos, 2012). Por essas razões, o uso de recursos de computador pode fornecer um uso mais frequente de AIPs por um número maior de pessoas. Uma forma direta de iniciar a validação de hierarquias de preferência por estímulos com estímulos digitais apresentados por computador seria comparar resultados de uma AIP com itens tangíveis e com figuras digitais

Portanto, a proposta desse estudo foi comparar hierarquias de preferência geradas com figuras digitais e com itens tangíveis com 14 crianças com desenvolvimento típico e nove crianças com deficiência intelectual. As figuras digitais foram apresentadas em uma tela de computador com o auxílio do programa Jogo da Escolha (Escobal et al., 2012) e os itens tangíveis foram apresentados sobre uma mesa. Como as figuras digitais não poderiam ser experienciadas da mesma maneira que os itens tangíveis, o acesso a um item nunca foi fornecido após uma resposta de escolha nos dois formatos.

\section{Método}

\section{Participantes}

Os participantes foram oito meninos e seis meninas com desenvolvimento típico, com idades entre 3 e 5 anos, que frequentavam uma pré-escola pública, e nove meninos com deficiência intelectual, com idades entre 9 e treze anos, que frequentavam uma escola pública 
para crianças com deficiências e transtornos globais do desenvolvimento. Um pré-requisito para participação era que os indivíduos não tivessem experiência anterior com métodos de avaliação de preferência.

\section{Ambiente e Materiais}

A Pesquisa foi conduzida em salas de aproximadamente $4 \mathrm{~m} \times 3 \mathrm{~m}$ nas escolas em que os participantes foram recrutados. Os materiais incluíam um computador portátil com acesso a Internet, uma mesa, três cadeiras, papel, caneta, folhas de registro, uma filmadora, e o programa Jogo da Escolha.

O Jogo da Escolha permite a criação de tarefas apresentadas por computador com dois ou mais estímulos apresentados simultaneamente. O Jogo da Escolha está localizado em um servidor na Universidade Federal de São Carlos (UFSCar) em www.lahmiei.ufscar.br/jogodaescolha.

\section{Estímulos Experimentais}

Oito itens tangíveis, divididos em materiais escolares (régua, lápis, apontador e borracha) e itens de lazer (adesivo, giz de cera, máscara e livro de colorir), e suas figuras digitais correspondentes (veja Tabela 1) foram usados nas avaliações. As figuras eram fotos digitais coloridas de cada item, gravados como arquivos Joint Photographic Experts Group (JPG) com tamanhos de $30 \mathrm{~Kb}$ a $40 \mathrm{~Kb}$, com $11 \mathrm{~cm}$ de largura por $9 \mathrm{~cm}$ de altura, tirados em um plano de fundo cinza.

\section{Procedimento}

Cada categoria (materiais escolares e itens de lazer) foi testada em uma Avaliação de Preferência com Escolha Pareada usando figuras digitais e itens tangíveis. Primeiramente, cada criança com desenvolvimento típico foi exposta a quatro sessões de AIP (duas avaliações de preferência com figuras digitais por computador e duas avaliações de preferência com itens tangíveis) que apresentavam 12 tentativas cada em um único dia. Um mês mais tarde, as crianças com deficiência intelectual foram expostas às mesmas quatro sessões em um único dia.
Como as crianças com desenvolvimento típico foram testadas primeiramente, seus pais e seus professores preencheram uma folha na qual poderiam indicar, entre 20 itens disponíveis (dez materiais escolares e dez itens de lazer), aqueles que eles acreditavam serem os favoritos de seus filhos/alunos. A partir das respostas individuais, duas listas foram criadas, uma com os quatro materiais escolares mais escolhidos e outra com os quatro itens de lazer mais escolhidos, conforme descritas acima. As mesmas listas foram então utilizadas com as crianças com deficiência intelectual para manter esse aspecto da pesquisa constante. Antes da aplicação das avaliações de preferência, foram fornecidos $15 \mathrm{~s}$ de exposição forçada a cada item para os participantes.

Duas matrizes distintas de avaliação de preferência, uma para materiais escolares (ver Tabela 1, Lista 1) e uma para itens de lazer (ver Tabela 1, Lista 2), com 12 tentativas cada, foram criadas para guiar a apresentação dos pares de estímulos. A ordem de apresentação de cada par foi predeterminada e contrabalanceada para que cada item em uma lista aparecesse com todos os outros itens da mesma lista, uma vez à esquerda e outra à direita. Para as duas avaliações, o acesso ao item após uma resposta não foi fornecido e a sequência de apresentação seguiu uma das matrizes previamente descrita (ver Tabela 1).

A preferência por materiais escolares (ver Tabela 1, Lista 1) foi avaliada primeiramente, seguida pela preferência por itens de lazer (ver Tabela 1, Lista 2). Metade dos participantes foi testada primeiramente com as figuras digitais e em seguida com os itens tangíveis; essa ordem foi invertida para a outra metade.

Avaliação de preferência com figuras digitais por computador. Para esse estudo, duas avaliações de preferência com figuras digitais por computador foram criadas no Jogo da Escolha digitando o nome da avaliação e o número de estímulos concorrentes (dois). Cada tentativa iniciava com a apresentação simultânea de duas figuras digitais diferentes na tela e a instrução "Escolha o que você mais gosta e aponte" fornecida pelo experimentador. Respostas de apontar eram seguidas por elogio fornecido pelo experi- 
Tabela 1

Matriz dos Pares de Apresentação

\begin{tabular}{|c|c|c|c|c|}
\hline \multirow[b]{2}{*}{ Tentativa } & \multicolumn{2}{|c|}{ Lista 1} & \multicolumn{2}{|c|}{ Lista 2} \\
\hline & Esquerda & Direita & Esquerda & Direita \\
\hline 1 & $-=$ & & & \\
\hline 2 & & & & \\
\hline 3 & -0 & & & \\
\hline 4 & & -0 & & \\
\hline 5 & & $-\infty$ & & \\
\hline 6 & & & & \\
\hline 7 & & & & \\
\hline 8 & -0 & & & \\
\hline 9 & & & & \\
\hline 10 & & & & \\
\hline 11 & & & & \\
\hline 12 & $\Rightarrow$ & -- & & \\
\hline
\end{tabular}


mentador e por um clique com o mouse sobre a figura escolhida realizado pelo experimentador, para manter as respostas de apontar dos participantes, de forma consistente, nos dois métodos. O programa registrava a resposta, retirava as figuras e apresentava a próxima tentativa.

Avaliação de preferência com itens tangíveis. Cada tentativa iniciava com a apresentação simultânea de dois itens tangíveis sobre a mesa e a instrução "Escolha o que você mais gosta e aponte" fornecida pelo experimentador. Respostas de apontar eram seguidas por elogio fornecido pelo experimentador. As respostas de escolha eram registradas pelo experimentador e por um observador independente treinado em uma folha de registro. $\mathrm{O}$ experimentador retirava os itens e apresentava a próxima tentativa.

Escolha final de um item. Após os participantes completarem as quatro AIPs, os oito itens tangíveis eram apresentados simultaneamente sobre a mesa e era apresentada a instrução "Escolha o que você mais gosta e aponte. Você pode ficar com esse item." Era apresentada uma única tentativa. $\mathrm{O}$ item apontado era registrado e o item era entregue ao participante por um segundo experimentador. Essa fase foi conduzida para comparar a escolha final com o item mais preferido nas AIPs anteriores.

\section{Medidas, Concordância entre Observadores e Análise de Dados}

Respostas de escolha foram registradas quando o participante apontava para um único estímulo. Se o participante apontasse para os dois estímulos, era introduzida uma instrução adicional para escolher e apontar para somente um dos estímulos.

Todas as sessões foram cronometradas. O tempo de execução das avaliações digitais foi obtido a partir dos registros do programa e o tempo de execução das avaliações sobre a mesa foi obtido das folhas de registro. As folhas de registro foram preenchidas pelo experimentador e por um observador independente treinado para cálculos de fidedignidade de tentativa por tentativa. A concordância foi calculada comparando os registros do experimentador e do observador independente para cada tentativa. Foi considerada concordância quando experimentador e observador registravam a mesma escolha. O número total de concordâncias foi somado, dividido pelo total de tentativas e convertido em percentual (Hall, 1974). A concordância entre observadores para todas as fases foi de $100 \%$.

Para propostas de análise de dados, uma correspondência foi contada se a porcentagem de escolhas de um item tangível e da figura digital correspondente foi idêntica ou diferiu em 0,17 .

Os coeficientes de correlação de Pearson também foram calculados para as escolhas de cada participante por materiais escolares e itens de lazer, separadamente. O coeficiente de Pearson foi usado para determinar a força das associações entre escolhas por figuras digitais e as escolhas por seus itens tangíveis correspondentes. O coeficiente de Pearson pode variar de +1 a -1 . O valor 0 indica que não há associação entre as duas variáveis. Valores maiores que 0 indicam uma associação positiva. Valores menores que 0 indicam associação negativa. A força das associações positivas foi classificada como pequena (de 0,10 a 0,29$)$, média (de 0,30 a 0,49 ) e grande (de 0,50 a 1,00). A força das associações negativas foi classificada como pequena (de $-0,10$ a $-0,29)$, média (de $-0,30$ a $-0,49)$ e grande (de $-0,50$ a $-1,00$ ).

\section{Validade Social}

A usabilidade e a satisfação com o Jogo da Escolha para avaliar preferência é uma medida que pode indicar aspectos relevantes relacionados com a validade social. Para avaliar esses aspectos, os professores das crianças com deficiência intelectual tiveram a oportunidade de criar testes no Jogo da Escolha após observar o experimentador e as sessões de AIPs com essas crianças. Então, foi solicitado que eles classificassem cada questão da Tabela 2 de 1 a 5 (1: muito insatisfeito; 2: insatisfeito; 3 : indiferente; 4: satisfeito; 5: muito satisfeito). A questão 14 deveria ser preenchida com sugestões ou comentários gerais acerca do programa. 
Tabela 2

Questões Apresentadas no Questionário de Satisfação Respondido pelos Professores

\begin{tabular}{cl}
\hline Questão & \multicolumn{1}{c}{ Declaração } \\
\hline Q1 & Nível geral de satisfação com a ferramenta. \\
Q2 & Interesse em continuar usando a ferramenta. \\
Q3 & Probabilidade de você indicar a ferramenta a outras pessoas interessadas. \\
Q4 & Clareza das mensagens na ferramenta sobre o sucesso ou fracasso de uma ação do usuário. \\
Q5 & Velocidade de resposta de uma ação do usuário. \\
Q6 & Facilidade de leitura das telas disponibilizadas. \\
Q7 & Facilidade no uso da ferramenta. \\
Q8 & Economia de tempo oferecida pela ferramenta na apresentação de escolhas em relação \\
Q9 & a apresentação com objetos tangíveis. \\
Q10 & Recursos financeiros requeridos para utilizar a ferramenta. \\
Q11 & Possibilidade da instituição em usar a ferramenta. \\
Q12 & Facilidade de acesso ao equipamento requerido para rodar a ferramenta dentro da instituição. \\
Q13 & Facilidade de usar a ferramenta em outros locais ou ambientes. \\
Q14 & O que seria uma ação principal corretiva que você poderia sugerir para melhorar a ferramenta? \\
\hline
\end{tabular}

\section{Resultados}

A porcentagem de escolha de cada item das duas categorias, materiais escolares e itens de lazer, está apresentada nas Figuras 1 e 2. Para seis dos 14 (43\%) participantes com desenvolvimento típico e para cinco dos nove (55\%) participantes com deficiência intelectual, num total de 11 dos 23 (48\%) participantes, o material escolar escolhido mais vezes foi o mesmo nas avaliações com itens tangíveis e com figuras digitais. Para nove dos 14 (64\%) participantes com desenvolvimento típico e para sete dos nove (78\%) participantes com deficiência intelectual, num total de 16 dos 23 (70\%) participantes, o item de lazer escolhido mais vezes foi o mesmo nas avaliações com itens tangíveis e com figuras digitais. Para sete dos 14 (50\%) participantes com desenvolvimento típico e para quatro dos nove (44\%) participantes com deficiência intelectual, num total de 11 dos 23 (48\%) participantes, o material escolar escolhido menos vezes foi o mesmo nas avaliações com itens tangíveis e com figuras digitais. Para oito dos 14 (57\%) participantes com desenvolvimento típico e para sete dos nove (78\%) participantes com deficiência intelectual, num total de 15 dos 23 (65\%) participantes, o item de lazer escolhido menos vezes foi o mesmo nas avaliações com itens tangíveis e com figuras digitais. Para alguns participantes, houve mais do que empate no estímulo escolhido mais vezes e no estímulo escolhido menos vezes.

A avaliação de preferência com figuras digitais por computador foi efetiva para identificar claramente um único material escolar escolhido mais vezes para 17 (74\%) participantes, um único item de lazer escolhido mais vezes para 19 (83\%) participantes, um único material escolar escolhido menos vezes para 14 (61\%) participantes e um único item de lazer escolhido menos vezes para 17 (74\%) participantes. Esse resultado é obtido quando, nas Figuras 1 e 2, somente uma barra preta é mais alta (para itens mais escolhidos) ou mais baixa (para itens menos escolhidos) do que todas as outras. 


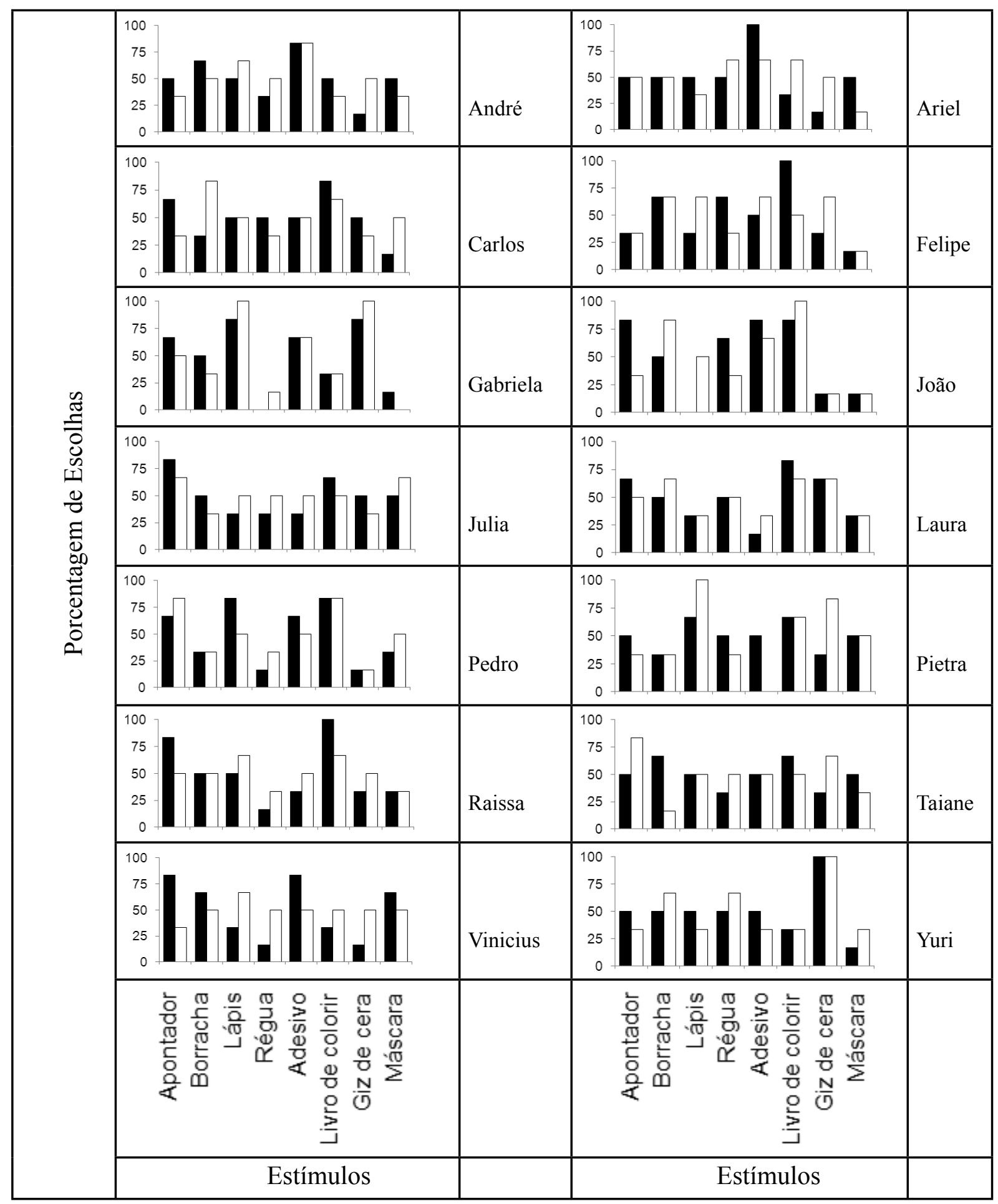

Figura 1. Resultados das avaliações de preferência para os participantes com desenvolvimento típico. Barras pretas indicam os resultados para figuras digitais; barras brancas indicam os resultados para itens tangíveis.

O item escolhido na escolha final foi um dos estímulos escolhidos mais vezes na avaliação de preferência com figuras digitais para oito dos 14 (57\%) participantes com desenvolvimento típico e para quatro dos nove $(44 \%)$ participantes com deficiência intelectual (ver
Tabela 3). Se forem considerados os dois estímulos escolhidos mais vezes, esses números aumentam para onze dos 14 (78\%) participantes com desenvolvimento típico e para sete dos nove $(78 \%)$ participantes com deficiência intelectual (ver Tabela 3). 


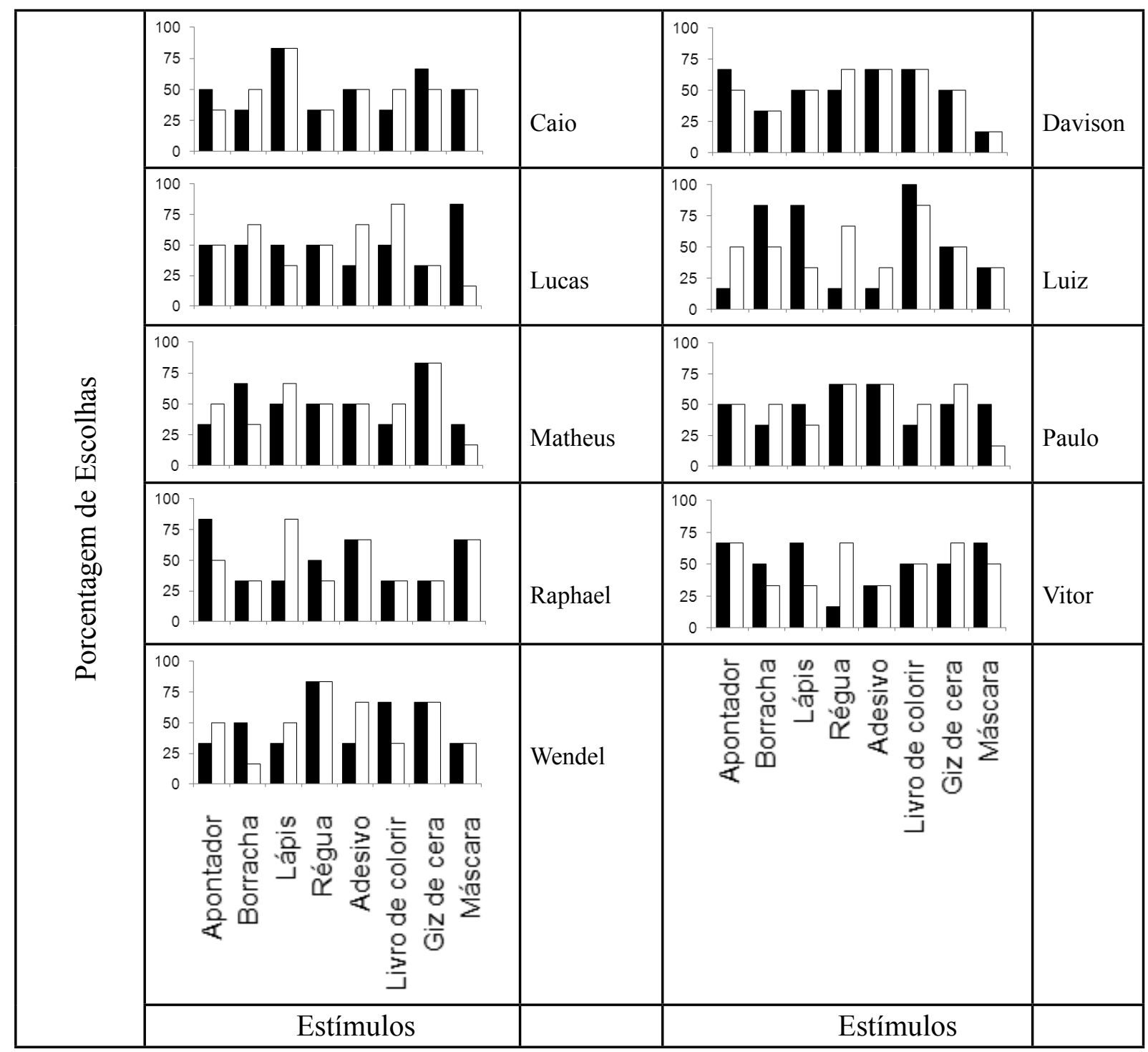

Figura 2. Resultados das avaliações de preferência para os participantes com deficiência intelectual. Barras pretas indicam os resultados para figuras digitais; barras brancas indicam os resultados para itens tangíveis.

Os coeficiente de correlação de Pearson (ver Tabela 4) mostram que para materiais escolares houve associações positivas para dez participantes, associações negativas para oito participantes e não houve associação para cinco participantes; para itens de lazer, houve associações positivas para 17 participantes, associações negativas para dois participantes e não houve associação para quatro participantes. As dez associações positivas para materiais escolares foram de força grande; para as 17 associações positivas para itens de lazer, 14 foram de força grande, 1 média e 2 pequenas. Para as oito associações negativas para materiais escolares, cinco foram de força grande, duas médias e uma pequena; para as duas associações negativas para itens de lazer, uma foi de força grande e uma pequena. 
Tabela 3

Item Final Escolhido para Cada Participante

\begin{tabular}{|c|c|c|c|c|c|}
\hline \multirow[b]{2}{*}{ Participante } & \multirow[b]{2}{*}{ Escolha Final } & \multicolumn{2}{|c|}{$\begin{array}{c}\text { Posição de Escolha } \\
\text { dos Materiais Escolares }\end{array}$} & \multicolumn{2}{|c|}{$\begin{array}{l}\text { Posição de Escolha } \\
\text { dos Itens de Lazer }\end{array}$} \\
\hline & & Figura & Tangível & Figura & Tangível \\
\hline Andre & Adesivo & & & 1 & 1 \\
\hline Ariel & Adesivo & & & 1 & 1 \\
\hline Caio & Giz de cera & & & 1 & 1 \\
\hline Carlos & Adesivo & & & 2 & 2 \\
\hline Davison & Livro de colorir & & & 1 & 1 \\
\hline Felipe & Giz de cera & & & 3 & 1 \\
\hline Gabriela & Giz de cera & & & 1 & 1 \\
\hline João & Livro de colorir & & & 1 & 1 \\
\hline Julia & Giz de cera & & & 2 & 4 \\
\hline Laura & Giz de cera & & & 2 & 1 \\
\hline Lucas & Livro de colorir & & & 2 & 1 \\
\hline Luiz & Lápis & 1 & 4 & & \\
\hline Matheus & Máscara & & & 3 & 4 \\
\hline Paulo & Livro de colorir & & & 4 & 3 \\
\hline Pedro & Livro de colorir & & & 1 & 1 \\
\hline Pietra & Livro de colorir & & & 1 & 2 \\
\hline Raissa & Giz de cera & & & 3 & 2 \\
\hline Raphael & Régua & 2 & 3 & & \\
\hline Tatiane & Livro de colorir & & & 1 & 2 \\
\hline Vinicius & Giz de cera & & & 4 & 1 \\
\hline Vitor & Giz de cera & & & 2 & 1 \\
\hline Wendel & Régua & 1 & 1 & & \\
\hline Yuri & Giz de cera & & & 1 & 1 \\
\hline
\end{tabular}

A Figura 3 mostra os valores de zero a cinco (representados pelas barras) dados por cada professor (T1 a T5) para cada questão (Q1 a Q13). Em geral, a avaliação dos professores para a ferramenta informatizada atingiu uma classificação de satisfeito a muito satisfeito $(88 \%$ das respostas). A maioria das questões recebeu uma pontuação 4 (satisfeito), o que corresponde a $46 \%$ de todas as respostas. Em seguida, $42 \%$ das questões recebeu a pontuação 5. As questões que receberam a pontuação 3 ou menos corresponderam a $12 \%$. Em relação a questão 14 , os professores T1, T2 e T4 não fizeram nenhuma sugestão ou comentário. T3 enfatizou que o programa é simples e fácil de usar e também escreveu que não requer habilidades técnicas específicas. T5 sugeriu o uso de cores mais claras. 
Tabela 4

Coeficiente de Correlação de Pearson para Cada Participante

\begin{tabular}{lccccc}
\hline Participante & Material Escolar & Itens de Lazer & Participante & Material Escolar & Itens de Lazer \\
\hline Andre & 0,00 & 0,57 & Caio & 0,83 & 0,00 \\
Ariel & 0,00 & 0,21 & Davison & 0,50 & 1,00 \\
Carlos & $-0,87$ & 0,50 & Lucas & 0,00 & $-0,51$ \\
Felipe & 0,00 & 0,32 & Luiz & $-0,70$ & 0,98 \\
Gabriela & 0,86 & 0,98 & Matheus & $-0,50$ & 0,86 \\
João & $-0,32$ & 0,94 & Paulo & 0,50 & 0,28 \\
Julia & 0,57 & 0,00 & Raphael & $-0,16$ & 1,00 \\
Laura & 0,50 & 0,94 & Vitor & $-0,40$ & 0,50 \\
Pedro & 0,64 & 0,89 & Wendel & 0,57 & 0,00 \\
Pietra & 0,82 & $-0,19$ & & & \\
Raissa & 0,50 & 0,82 & & & \\
Tatiane & $-0,50$ & 0,50 & & & \\
Vinicius & $-0,67$ & 0,00 & & & \\
Yuri & 0,00 & 0,92 & & & \\
\hline
\end{tabular}

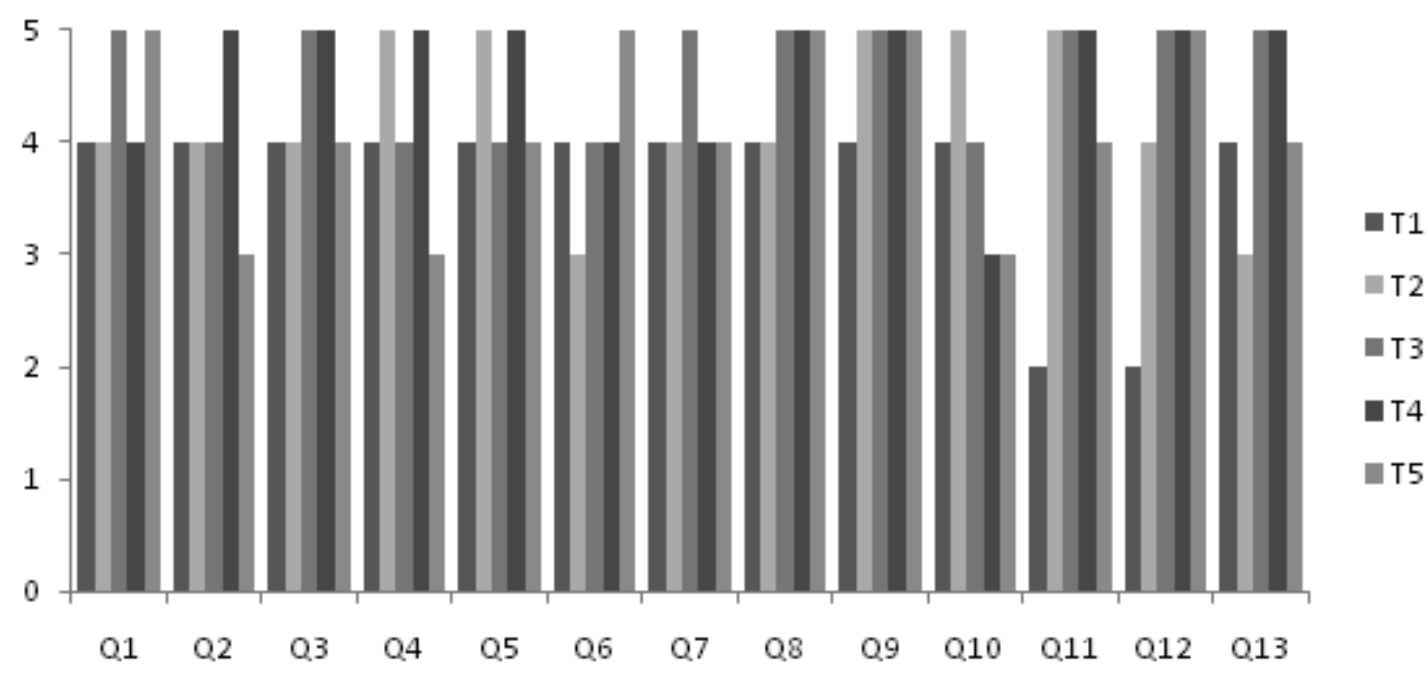

Figura 3. Resultados do questionário apresentado aos professores das crianças com deficiência intelectual. Os resultados são mostrados de acordo com os pontos (de 0 a 5 no eixo Y) dados por cada professor (T1 a T5) para cada questão (Q1 a Q13 no eixo X). As barras representam o valor dado por cada professor para cada questão.

\section{Discussão}

A proposta desse estudo foi comparar hierarquias de preferência geradas com figuras digitais e com itens tangíveis com 14 crianças com desenvolvimento típico e nove com deficiência intelectual. As figuras digitais foram apresentadas em uma tela de computador e os itens tangíveis sobre a mesa. Os resultados indicaram que os dois métodos (figuras digitais e itens tangíveis) geraram os mesmos estímulos mais escolhidos para a maioria dos participantes. Os 
coeficientes de correlação de Pearson também indicaram que os dois métodos de avaliação geraram hierarquias de preferências similares para a maioria dos participantes, considerando que o número de associações positivas foi maior que $o$ número de associações negativas ou sem associações, sendo a maioria das associações positivas de força grande.

A avaliação de preferência por computador foi efetiva para identificar claramente um único material escolar mais escolhido para 17 dos 23 participantes e um item de lazer mais escolhido para 19 dos 23 participantes, rapidamente e com baixo custo de resposta. Esses resultados são semelhantes aos encontrados por Groskreutz e Graff (2009), no qual os três formatos de avaliação (tangível, figura com acesso e figura sem acesso) indicou os mesmos itens mais escolhidos para 4 dos 5 participantes.

O estudo de Higbee et al. (1999) mostrou variações na correspondência quando eles conduzira avaliações de preferência com estímulos múltiplos com dois adultos diagnosticados com deficiência intelectual usando itens tangíveis e cartões com figuras impressas representando os mesmos itens. A avaliação com itens tangíveis produziu maior variação na porcentagem de seleção que a avaliação com figuras, o que gerou um hierarquia de preferência mais forte e mais clara. Os autores discutem que os estímulos previstos pela avaliação tangível foram reforçadores mais potentes que aqueles previstos pela avaliação com figuras. Estudos futuros poderiam testar se os itens identificados pela avaliação com figuras digitais usada nesse estudo funcionariam como reforçadores em situações de ensino.

Uma variável que pode interferir na emissão do comportamento de escolha é o meio pelo qual a escolha é feita (Escobal \& Goyos, 2008). Apontar pode ter um custo de resposta menor do que, por exemplo, dizer o nome do item ou responder a perguntas complexas. Parece que a resposta de apontar para o item preferido usada nesse estudo representa uma topografia adequada de resposta.

O uso das mesmas listas de estímulos para todos os participantes ao invés de listas individuais pode ter mascarado os resultados. Para alguns participantes, mais do que um item foi escolhido mais vezes, provavelmente porque nenhum item era preferido. Replicações futuras da avaliação de preferência com figuras digitais poderiam utilizar listas individuais para cada participante.

Esse estudo usou materiais escolares e itens de lazer. Estudos futuros poderiam testar a generalização dos resultados para outros estímulos, tais como tarefas acadêmicas ou de trabalho, através da apresentação de vídeos digitais. Itens diferentes de categorias diferentes (alimentos, brinquedos) também poderiam ser testados, com diferentes densidades de reforçamento, no começo e no fim do procedimento para avaliar os efeitos da escolha no desempenho dos organismos.

Uma possível limitação desse estudo é que as habilidades de emparelhamento entre figuras digitais e os itens tangíveis não foram testadas. Entretanto, o item selecionado na escolha final correspondeu à primeira ou segunda figura digital mais escolhida na avaliação de preferência por computador para 18 dos 23 participantes, o que pode indicar que os itens tangíveis e as figuras digitais correspondentes pertenciam a mesma classe de estímulos equivalentes. Mas é importante lembrar que não apresentar essas habilidades de emparelhamento poderia explicar a falta de correspondência para os outros participantes.

Conyers et al. (2002) conduziram um estudo para avaliar como as respostas de escolha eram influenciadas por modalidades diferentes de estímulos (objetos, figuras e descrições verbais). Oportunidades de escolha foram apresentadas para nove indivíduos com deficiência intelectual em uma avaliação de preferência com escolha pareada. Cada par de itens era apresentado para cada participante em três condições (itens tangíveis, figuras desses itens e os nomes) usando um delineamento reverso. Primeiramente, a avaliação foi conduzida com itens comestíveis, e depois com itens não comestíveis. Os participantes também foram expostos a um teste para medir suas habilidades em tarefas de discriminação simples e condicional. Eles selecionaram seus itens preferidos consistentemente tanto com figuras quanto com objetos e suas habilidades de fazer essas escolhas foram previstas com $94 \%$ de 
acurácia pelas habilidades de discriminação. Os achados sugerem que a modalidade dos estímulos pode afetar a acurácia de uma avaliação de preferência, e que a revisão sistemática de habilidades básicas de discriminação pode ser usada para predizer a efetividade de métodos diferentes para essa população. Estudos futuros com a avaliação de preferência por computador poderiam medir as habilidades de emparelhamento entre figuras digitais e itens tangíveis.

Outra possível limitação foi que as respostas de escolha não foram seguidas da entrega do item. Conforme afirmado por Groskreutz e Graff (2009), para alguns indivíduos, o acesso ao item escolhido pode não ser necessário durante as avaliações de preferência, mas eles podem, em algum ponto, parar de responder preferencialmente após apresentações repetidas das oportunidades de escolha. Nesses casos, esquemas de reforçamento de intervalo podem ser utilizados para manter o responder preferencial, o que não iria adicionar muito tempo adicional à avaliação.

Esse estudo examinou a avaliação de preferência por computador para identificar itens de preferência. Os resultados sugerem que esse método pode ser viável e acurado para identificar itens de preferência. $\mathrm{O}$ uso de uma ferramenta informatizada para avaliar preferência também apresenta importantes implicações práticas: o armazenamento de um vasto banco de dados de estímulos, representação de situações da vida real e apresentação de estímulos e registro das respostas de escolha de forma automática. Pesquisas futuras poderiam usar uma avaliação de preferência de estímulos digitais por computador similar à usada nesse estudo para examinar preferências por atividades, o que constitui a área na qual essas avaliações seriam mais úteis, por produzir economia de tempo e de esforço (Groskreutz \& Graff, 2009; Hanley et al., 1999). O tempo médio gasto nas avaliações de preferência por computador foi de 2 minutos e 13 segundos e para itens tangíveis sobre a mesa foi de 2 minutos e 46 segundos. Essa diferença tende a crescer conforme o número de estímulos e as oportunidades de escolha também crescem.

De acordo com a avaliação dos professores, pode-se dizer que a avaliação de preferência por computador é uma forma poderosa e fácil de usar para avaliar preferência, com economia de tempo, o que permite um uso mais frequente desses métodos. É essencial, no entanto, encorajar os praticantes (professores, pais e cuidadores do setor de saúde) a avaliarem e identificarem reforçadores para indivíduos com deficiência intelectual com regularidade e transformar o procedimento de identificação de reforçadores uma parte padrão do currículo desses indivíduos (Escobal et al., 2010).

\section{Referências}

Carr, J. E., Nicolson, A. C., \& Higbee, T. S. (2000). Evaluation of a brief multiple-stimulus preference assessment in a naturalistic context. Journal of Applied Behavior Analysis, 33, 353-357.

Clausen, K. (2006). Identifying preferences and creating motivation to learn for children with autism spectrum disorders. Carbondale, IL: Center for Autism Spectrum Disorders.

Conyers, C., Doole, A., Vause, T., Harapiak, S., Yu, D. C. T., \& Martin, G. L. (2002). Predicting the relative efficacy of three presentation methods for assessing preferences of persons with developmental disabilities. Journal of Applied Behavior Analysis, 35, 49-58.

DeLeon, I. G., \& Iwata, B. A. (1996). Evaluation of a multiple-stimulus presentation format for assessing reinforcer preferences. Journal of Applied Behavior Analysis, 29, 519-533.

Escobal, G., Elias, N. C., \& Goyos, C. (2012). Jogo da Escolha: Ferramenta informatizada para avaliar preferências por reforçadores. Temas em Psicologia, 20(2), 451-458. doi:10.9788/TP2012.2-13

Escobal, G., \& Goyos, A. C. N. (2008). Análise das variáveis determinantes do comportamento de escolha entre alternativas de trabalho em adultos com deficiência mental. Revista Brasileira de Análise do Comportamento, 4, 71-87.

Escobal, G., Macedo, M., Duque, A. L., Gamba, J., \& Goyos, C. (2010). Contribuições do paradigma de escolha para identificação de preferências por consequências reforçadoras. In M. M. C. Hübner, M. R. Garcia, P. R. Abreu, E. N. P. De Cillo, \& P. B. Faleiros (Eds.), Sobre comportamento e cognição. Santo André, SP: ESEtec. 
Fisher, W. W., Piazza, C. C., Bowman, L. G., Hagopian, L. P., Owens, J. C., \& Slevin, I. (1992). A comparison of two approaches for identifying reinforcers for persons with severe and profound disabilities. Journal of Applied Behavior Analysis, 25, 491-498.

Groskreutz, M. P., \& Graff, R. B. (2009). Evaluating pictorial preference assessment: The effect of differential outcomes on preference assessment results. Research in Autism Spectrum Disorders, 3, 113-128.

Hall, R. V. (1974). Managing behavior - behavior modification: The measurement of behavior. Lawrence, KS: H \& H Enterprises.

Hanley, G. P., Iwata, B. A., \& Lindberg, J. S. (1999). Analysis of activity preferences as a function of differential consequences. Journal of Applied Behavior Analysis, 32, 419-435.

Higbee, T. S., Carr, J. E., \& Harrison, C. D. (1999). The effects of pictorial versus tangible stimuli in stimulus-preference assessments. Research in Developmental Disabilities, 20(1), 63-72.
Pace, G. M., Ivancic, M. T., Edwards, G. L., Iwata, B. A., \& Page, T. J. (1985). Assessment of stimulus preference and reinforcer value with profoundly retarded individuals. Journal of Applied Behavior Analysis, 18, 249-255.

Piazza, C. C., Fisher, W. W., Bowman, L. G., \& Blakeley-Smith, A. (1999). Identifying and assessing reinforcers using choice paradigms. In P. M. Ghezzi, W. L. Williams, \& J. E. Carr (Eds.), Autism: Behavior analytic perspectives. Reno, NV: Context Press.

Roane, H. S., Vollmer, T. R., Ringdahl, J. E., \& Marcus, B. A. (1998). Evaluation of a brief stimulus preference assessment. Journal of Applied Behavior Analysis, 31, 605-620.

Recebido: 14/06/2013

$1^{a}$ revisão: $16 / 10 / 2013$

Aceite final: 08/11/2013 